\title{
MATTER

\section{Mathematics in the middle: \\ The relationship between measurement and metamorphic matter}

\author{
Elizabeth de Freitas \\ Manchester Metropolitan University \& Adelphi University \\ DOI: https://doi.org/10.1344/jnmr.v2i2.35888
}

\begin{abstract}
This paper revisits philosophical questions regarding the relationship between mathematics and matter. I briefly present four contrary and contemporary perspectives on the speculative force of mathematics, as a provocation for further discussion on the subject of sciento-metrics. I first consider the ideas of the philosopher Quentin Meillassoux, as a way of setting the stage for various kinds of materialist philosophies of mathematics. I then turn to the ideas of two mathematicians - Fernando Zalamea and Giuseppe Longo - and a computer scientist - Gregory Chaitin - and explore how their discussions of contemporary mathematical practice offer important insight (and twist) regarding the relationship between mathematics and matter.
\end{abstract}

\section{Keywords}

Mathematics; speculation; science; realism; Meillassoux; Longo; Chaitin; Zalamea. 


\section{Introduction}

In 1960 the scientist Eugene Wigner (1902-1995) wrote a controversial paper called "The unreasonable effectiveness of mathematics in the natural sciences" (Wigner, 1960). Wigner's paper was read as problematically positing a kind of magical or transcendent role for mathematics, in its capacity to describe and predict physical phenomena. Wigner suggested that the accuracy of mathematical formulations was an epistemological "miracle" indicating that the "laws of nature must already be formulated in the language of mathematics" (Wigner, 1960) ${ }^{1}$. He claimed that mathematics involved the free creation and manipulation of concepts, and its "appropriateness" was a "wonderful gift" in a complex chaotic world with little regularity and invariance. Notably, as Jose Ferreirós (2018) points out, Wigner was an important figure in developing effective mathematical methods for quantum physics, which involved shifting from the classical calculus to new algebraic 'group methods'. By the 1930s many physicists resented the displacement of the calculus, which cranked out actual solutions, for the more abstract structural approach of modern algebra and its meta-level patterns. They were concerned that the new goal of physics had become the search for compelling algebraic models and super symmetries and had lost touch with the bedrock of empirical reckoning. This "plague of groups" or "group pest" infestation, transformed the everyday practice of physics (Ferreirós, 2018).

Wigner's perspective on "the unreasonable effectiveness of mathematics" seems to have also been inspired by the turn to axiomatics and formalist qualitative methods, led by David Hilbert (1862-1943), and perhaps by his involvement in the Manhattan Project, and the development of the Atomic bomb. This $20^{\text {th }}$ century mixture of modern algebra, axiomatics, war efforts and quantum science forms the background for his 1960 essay. ${ }^{2}$ Wigner's suggestion of a hidden mathematical language yet to be fully translated suggests that matter is encoded or scripted by symbolic form, and humans

\footnotetext{
${ }^{1}$ He attributes this perspective originally to Galileo.

2 It was John Von Neumann (1903-1957) who spurred Wigner on to apply group theory to quantum mechanics and the two went on to participate in the Manhattan Project and the development of the Atomic bomb (Scholz, 2006). 
are the interpreters who are more or less skilful at deciphering it. ${ }^{3}$ The Anthropologist Vicki Kirby (2011) is critical of approaches that either mystify mathematics as miracle or treat mathematics as pure language game detached from the real. She argues that each is characterized as anthropocentric: the first imagines that the earth is there to serve humans, whose magical mathematics aims to control it (reductive scientism, or mathematical deism); the second imagines that the earth is beyond reach and unencounterable, cloaked in a cultural veil of human mathematics (social constructivism). Kirby suggests instead an approach that dethrones the anthropocentrism of these two traditions, and seeks a new empiricism that remixes mathematics and matter:

Measure would then not only be the anthropocentric habit inscribed in Protagoras' aphorism 'man is the measure of all things' nor reflect a unique human capacity. Instead, measure would be a tendency or potentiality of matter. Geometry, for instance, would be a more material mingling of geo and metric. For Kirby, too much of socio-cultural theory forecloses this possibility by defining geometry against geology, language against matter, mathematics as a representation that codes matter from without. (de Freitas, 2016a, p. 656)

Kirby (2011) provokes us to consider corporeality more generally as 'calculating and thinking material through and through' so much so that the very nature of corporeality is 'to mathematize, represent, or intelligently take measure of itself' (p. 63). She demands that we reckon with the way that matter and measurement are part of a metamorphic mixture, open to remixing, reformulating, and altered modes of bodying. This ensures that mathematics remains in the world (rather than transcends it) and emphasizes a pluralist new materialist mathematics. Accordingly, mathematics remains part of the metamorphic mixture of matter, and cannot detach itself from the world, to rise above, as inert, static, and apolitical.

\footnotetext{
${ }^{3}$ Philosophers of science have spent centuries discussing matter-mathematics mixtures, often using the term 'realist' to characterize the belief that the mathematics is 'out there' in some empirical sense, or that mathematics "inheres" in the physical world. These claims are usually contrasted with alternative appeals to formalism or idealism, both of which detach mathematics, in different ways, from the material world. There are epistemic and ontological dimensions to these positions, and variations have emerged over the decades (see Benacerraf \& Putnam, 1964 and Tymoczko, 1998 for foundational work. For instance, Nancy Cartwright has argued for a pluralist realism, insofar as she contests the law-like nature of mathematicsphysics relationships, in favour of a "capacity" that inheres in the "dappled world".
} 
In this paper, I explore recent proposals for rethinking the ontological mixture of mathematics and matter. I discuss thinkers who engage closely with the specifics of mathematical practice, whilst keeping the ontological question about mathematics and matter front and center. I examine four contemporary perspectives on the nature of mathematics, as a provocation for further discussion on the topic of scientometrics, which is the title of the section launched with this issue of the journal. I first consider the ideas of the philosopher Quentin Meillassoux, as a way of setting the stage for various kinds of materialist philosophies of mathematics. I then turn to the ideas of two mathematicians - Fernando Zalamea and Giuseppe Longo - and a computer scientist - Gregory Chaitin - and explore how their discussions of contemporary mathematical practice offer important insight (and twist) regarding the relationship between mathematics and matter.

My aim is to highlight the distinctive insights of each of these four thinkers, regarding the material practice and speculative reach of contemporary mathematics. All four attend in different ways to the onto-epistemic foundations of mathematics, focusing on either the speculative power of mathematics or the corporeal-material dimension of mathematical activity. For Meillassoux, mathematics is essential in framing his "speculative materialism" and pursuit of the absolute necessity of contingency, while Chaitin presents himself as a modern Pythagorean, and reads contemporary mathematics through computing machines. Zalamea follows a Peircian pragmatist approach, tracking conceptual transits across the field, and Longo defends the interval and the continuous as fundamental modes of mathematical materiality. There are affinities between these approaches, in that each draws on contemporary mathematics for insight into socio-material problems, but they also differ significantly in where they place the human. I am interested in how we might tap their insights and cobble together a new materialist philosophy of mathematics so that questions about human mathematical ability might be considered in the context of a broader posthumanist opening onto the mathematiz-ability of the world. In other words, I seek ways of studying human mathematical habits, often conceptualized in sociological, philosophical, and psychological theories, as part of an earthly, worldly, and even cosmic mathematical ontology. The distribution of mathematical ability across complex ecologies opens up the debate about mathematical ontology in new ways, 
links to current concerns about algorithmic contingency, and urgently demands fresh insight from the post-humanities. I briefly survey these four approaches here, so that we might consider the distinctive ways they pursue the speculative power of mathematics.

\section{Speculative mathematics}

Although Wigner (1960) saw the empirical success of mathematics as following "the empirical law of epistemology", he also avows formalist foundations for the free play of mathematical ideas. Hilbert's formalist program was felt far and wide, but especially in modern algebra, where the speculative and generative force of mathematical invention was strongly evident. One can see in the new coupling of physics and algebra in the 1930s, the emergence of new conceptual mixtures that are in some strong sense entirely unimaginable from within past mathematics. In this way, we might use the term 'speculative mathematics' as a stand-in for hypothetical or inventive mathematical ideas, the kind of activity that brings forth a new mathematical object and then builds a somewhat altered and robust mathematical theory around it. But if the 'speculative' is to mean more than hypothetical and creative within a given discourse, and instead designates something with more of an ontological bite, then we need to consider its implications.

The metaphysical 'speculative' is typically used to reference pre-Kantian philosophies that allowed themselves the freedom to speak about that which was beyond the reach of human knowledge. Pythagorean declarations that "all is number" come to mind this is a speculative declaration which sounds an awful lot like dogmatic metaphysics, and precisely the kind of mysticism which Kant's project critiques. And yet the "ontological turn" we have witnessed across the post-humanities suggests that there are new metaphysical urges all around us, as well as keen interest to map the power of the speculative. If, as some claim, we are now breaking with the long legacy of Kant and his insistence on the filtering faculties of human judgment, which disallow any 'real' encounters with the world, or in the least updating this notion of a filtering faculty in more-than-human terms, it seems rather important that we take up and discuss proposals for the speculative reach of mathematics. 
In Après la finitude (2006/2008), Meillassoux argues that post-Kantian correlationism (between thought and being) undermined the speculative import of mathematics. He points to the "Galilean revolution" in scientific method in which mathematics became central to Western science when the world was newly understood and accessed through its mathematizable qualities. Many historians point to this revolution as the founding of contemporary science. The aim for Meillassoux, however, is to show how the Galilean revolution, which decenters the human within the solar system, entails a mathematizing of the world that bore within it the "possibility of uncovering knowledge of a world more indifferent than ever to human existence, and hence indifferent to whatever knowledge humanity might have of it" (Meillassoux, 2008, p.116). It is precisely this mathematization of nature, or rather the possibility of this mathematization, that gives purchase to scientific statements of fact about the world prior to or after humankind, according to Meillassoux. In other words, there is a certain facticity to the world that is larger than human knowledge, but that subsumes human knowledge precisely because of its speculative tendency. Mathematical science effects a radical decentering - "the decentering of thought relative to the world within the process of knowledge" (Meillassoux, 2008, p.115). It is this "within the process of knowledge" that substantiates facticity that is not merely correlational or conditional on the human faculties.

If Kant's critical project was meant to expose the naivety of previously dogmatic speculative philosophies, in which empirical fact and metaphysics commingled without adequate policing of the conditions of knowledge, he also shut down the speculative force of science itself. Meillassoux sees the Kantian critical project as a kind of therapy, a solace meant to comfort humans and alleviate their anxiety in the face of the radical decentering of human thought achieved through the speculative character of scientific knowledge. ${ }^{4}$ Thus the speculative is precisely what achieves a "non-correlational mode of knowing" in empirical inquiry, a kind of knowing that is more than human insofar as it refuses the Kantian conditions of knowledge (Meillassoux, 2008, p.119). The tragedy for philosophy, accordingly, was to abort the Galilean scientific revolution and follow Kant, wrongly denying the speculative import

${ }^{4}$ He states that his work answers the question: "How is a mathematical science of nature possible?" - a science that avoids the metaphysical and the correlationalist? (p. 128). 
of scientific knowledge in encountering the real, denying the robust capacity of the world to be multiply-mathematized (mathematiz-ability). Philosophy erred towards Kantian transcendental idealism, when it should have invested in the speculative nature of mathematics and science, pursuing what Meillassoux calls a "speculative materialism".

This kind of materialism is often aligned with philosophical realisms, like that of Graham Harman. ${ }^{5}$ For Meillassoux, who prefers to not use the term realism, mathematical statements are the best way to plug into the absolute necessary contingency of the world, and it is this emphasis on "necessary contingency" that can make them speculative in their scope. The concept of contingency is key for rethinking the way in which mathematics and matter are mixed. Note that Meillassoux is focused on absolute contingency rather than mere historical contingency, and he dismisses probabilisms and aleatory reason, for totalizing the possible. He turns away from probability and towards set theory, stating: "the most powerful conception of the incalculable and unpredictable event is provided by a thinking that continues to be mathematical - rather than one that is artistic, poetic, or religious. It is by way of mathematics that we will finally succeed in thinking that which, through its power and beauty, vanquishes quantities and sounds the end of play." (p. 108). In other words, he propounds that contingency comes in two modes, the first is finite/historical (captured by probability) and the second is the Cantorian 'transfinite': the first is an empirical contingency that refers to the precariousness of any given mathematization. The second is an absolute contingency that asserts a non-being that may never be realized, but is elaborated in particular mathematizations.

Meillassoux (2008) is not arguing for the absolute truth of mathematics, but for "the absolute scope of mathematics" (p. 125-126). And this is meant to grant mathematics a certain autonomy in its grasping tendencies - in other words, it can go beyond any human constructed correlation between world and model. This philosophy is not

\footnotetext{
${ }^{5}$ Barad's commitment to a relational ontology might seem to put her squarely in the target zone for Meillassoux's critique of the correlationists, but since she breaks with 'social constructivism' and human exceptionalism, and she explores the acausal world of quantum field theory, I think there are ways to consider these as kindred projects in certain aspects. See also Dolphijn \& Van der tuin (2012) and de Freitas (2017). The role of mathematics in various agential realisms, such as Karen Barad or Bruno Latour, is not as well developed as it is in Meillassoux, although Barad $(2007,2017)$ seeks to show how the world may be investigating itself mathematically, how creatures "do mathematics" not as algorithmic rule-followers, but as more-than-human "thought experiments"(Barad, 2017, np)
} 
about a mathematics that determines or encodes the world, but rather the claim is that the world possesses an inherent capacity to be mathematized. It's crucial to state loudly that the term "mathematizability" does not and cannot designate a pre-given particular mathematics waiting to be actualized. In some sense, mathematics actually safeguards the necessity of contingency. He makes this explicit when stating: "Whatever is mathematizable can be posited hypothetically as an ontologically perishable fact existing independently of us. In other words, modern science uncovers the speculative but hypothetical import of every mathematical reformulation of our world." (Meillassoux, 2008, p. 117). Notably, mathematics partakes of the linked ontological tendencies of the hypothetical, the necessary, and the speculative.

Meillassoux convincingly argues that post-Kantian critical philosophy, despite the good work of this project in fighting the ideological dogmatism that underpins metaphysics, has become a kind of "skeptical fanaticism". In contrast, he shows how speculation is not a regretful or negative act of straying from the real, but rather accentuates and affirms thought's capacity to become radically alien. This approach links with but diverges from the ideas of Badiou (2006) who emphasizes the capacity of mathematics to make thought alien or non-human. I think the project of Meillassoux is helpful in its attempt to defamiliarize mathematics, and to consider its potential as a radical worlding process unto itself. Below I discuss his focus on the Cantorian transfinite, and I revisit the contribution of Galileo, to explore corporeal questions about matter-mathematics mixtures.

\section{Foundational tendencies}

Galileo's revolutionary contribution was that he coupled mathematics with motion in ways that furnished a scientific dynasty and a frenzy of mathematizing (Johnson, 2008). This is philosophically important for a number of reasons, most significantly because the revolution (a collective achievement) broke with the Aristotelian and Euclidean dictum that separated the mathematical concept (as concept) from time and motion (Châtelet, 2000). The mathematics of motion - accurate or otherwise plays a highly significant role in any historical account of the relationship between mathematics and matter. Galileo's seminal inclined plane experiment, for instance, 
centered mathematics in the study of motion, and was considered by many historians to be emblematic of the emerging mathematical paradigm of European experimental science (Gribbin, 2002). The experiment, as recounted in 1638, sets a bronze ball rolling down a carved groove along the length of a 20 foot-long piece of wood. Chalk marks were made at equal distances along the piece of wood, and a water-clock was used to measure the time when the ball passed each of the chalk marks. Each time the ball passed a chalk mark, the amount of water was removed and weighed; the measurement of time was equated to the measure of the weight of the water.

Many have debated whether and how Galileo actually produced this empirical result. In the 1950s the historian of science Alexandre Koyré argued that there were so many sources of error that it was dubious that Galileo had actually performed the experiment (Koyre, 1977) ${ }^{6}$. How could he have measured time intervals that were a fraction of a second? But in the 1970s, historian Stillman Drake examined unpublished Galilean documents and found some that clearly indicated an experiment had indeed been performed. In response to Koyré's criticism, and based on archival evidence, Drake $(1975,1978)$ surmised that the measurement of time was achieved using music and not a water-clock. He argued that musicians and conductors divide time into equal portions with great precision for long periods of time without thinking of seconds or any other standard unit. He pointed out that a conductor "maintains a certain even beat according to an internal rhythm, and he can divide that beat in half again and again with an accuracy rivaling that of any mechanical instrument" (Drake, 1975). Using a simple tune that had two beats per second, Drake himself demonstrated how you could mark the location of the descending ball at the second beat of the rhythm and refine the marks after a few trials. Measurement of the various distances travelled during these two-beat counts revealed the effect of gravity on free-falling bodies.

This story is telling for a number of reasons. Drake shows how the actual empirical act of investigation involved space as a function of time (equal beats of time are used to show differences in distance). Thus he shows how time is the engine of the experiment, the independent variable. But more pertinent to the argument of this paper, is the fact that the most compelling explanation for how Galileo actually

\footnotetext{
${ }^{6}$ Notably, Wigner (1960) references this research.
} 
completed this seminal experiment involves the human body and its tacit engagement with duration and rhythm. We see the strange marriage of number and time that infuses the act of experimentation and measurement. Of course the act of measuring is implicated in the findings, but what Drake shows us about this experiment is not simply that facts are produced through human intervention; he points to the force of time as that which animates matter, and he shows how Galileo plugs into the rhythms of corporeal duration - in all their multiplicity and modulation - in order to perform his experiment. This perspective resonates with other historical accounts of developments in physics and mathematics, such as those discussed by Gilles Châtelet, which has informed my work on sympathetic coordination in mathematical behaviour (de Freitas et al, 2019). Châtelet (2000) looks historically for the emergence of new mathematical diagrammatic gestures over the centuries, tracking the "physicomathematics" of human invention. With reference to Galileo, he writes:

At first sight this physico-mathematics does appear to be an axiomatic giving precise form to the system of equivalence between mathematical concepts and physical concepts. To understand the revolutionary coup that installs this axiomatics is to discover the proximity of two horizons made up of virtual determinations which exceed the current set of explicit determinations and which still remain available for examination. Conceived as an apprenticeship, as a Promethean impulse, and not as a combinatorial manipulation of beingsin-the-world, or as an 'abstract game', mathematics necessarily fulfils itself in physics. It is in these terms that we should understand Galileo's audacity in daring to bring the boundary forms of pure geometry into contact with the world of moving bodies (Châtelet, 2000, p. 4).

And yet for Meillassoux, perhaps following his early mentor Badiou, the interest in a mathematics-matter mixture lies in the set-theoretic foundations of mathematics. In other words, he doesn't dwell in the material practice of a physico-mathematics, but instead turns to set theory and its role as a foundation ("condition") for the speculative reach of mathematics and the speculative power of knowledge. He seeks the speculative force of mathematics in the capacity of set theory to render the infinite, 
rather than in the processual nature of materiality. He will summarize the speculative import of mathematics in the following two claims:

1. "Every mathematical statement - precisely insofar as it is mathematical - is not necessarily true, but absolutely possible." (Meillassoux, 2008, p. 126, italics added,). That is to say, mathematical statements are not necessarily true, since such a claim would be a form of speculative idealism, and would pander to a kind of reductive logic, while Meillassoux is interested in a speculative materialism. And so he claims that mathematical statements are instead absolutely possible, because they operate as hypothetical systems structured through necessity, in a world of absolute contingency.

2. For Meillassoux, some mathematizations are better than others insofar as they substantiate the nontotalizability of worlds. There is one particular mathematical theorem that both exemplifies and assures the speculative import of mathematics. This theorem comes from Georg Cantor's (1845-1918) attempts to refine the methods of mathematics using set theory. This a theorem "that allows us to maintain the nontotalizability of the transfinite" (Meillassoux, 2008, p. 127). For Meillassoux, this theorem must be considered both absolute and unconditionally necessary. As such it then ensures that we do more than embrace the contingency of the world, but instead grasp the necessity of contingency. Mathematics in this instance is an activity that affirms the necessity of contingency. Cantorian mathematics helps us resolve Hume's problem of empiricism, with an ontology that emerges through the principle of unreason or factiality. It is the mathematics of Cantor's set theory, and his "detotalization of the possible" (p. 110), that answers Hume's problem. The "superimmensity of the chaotic virtual" cannot be measured by any number, finite or infinite (p. 111); The laws of nature are stable for no reason.

I want to suggest that this way of conceiving the speculative import of mathematics both helps and hinders our efforts to think about mathematiz-ability. On the one hand, I understand Meillassoux's project as an attempt to affirm the (limited) truth value of human science, while denying the privilege or right to claim that such knowledge is a mark of human achievement. We cannot claim correlationist truth nor metaphysical truth. Cantorian mathematical knowledge emerges in the material world and is not 
only a human constructed knowledge, capable of thinking the speculative outside of thought. Humans are simply lucky (or unlucky) to comprehend the material world stability of natural laws is not necessary, but is the case. Scientific practice can achieve this feat, if it avoids the probabilisms of aleatory reason, because it is an inherently mathematizing kind of activity that can dethrone the human subject and detotalize number. That being said, it follows that there might be worlds where science does not flourish, worlds found perhaps in certain examples of "extro-science fiction", but these seem rather impossible to conceptualize (Meillassoux, 2015).

The 'materialism' of this speculative materialism might seem rather thin to those thinkers focused on the materiality of mathematical practice. For instance, one might look more carefully at mathematical practices for how they engage a sort of free intensive force in the 'batter itself' that can morph into various forms of measure. This perspective brings us back into the mess of material practices and minor mathematical gestures, back to the kind of close reading that Gilles Châtelet performed, when seeking examples of inventive physico-mathematics. Despite the importance of foundations, I think the absolute scope of mathematics should be evident in diverse mathematical practices, rather than only evident in the famous Cantorian method for marshalling the transfinite. I suspect that the mathematics of non-totalizable worlds probably also lives in more mundane and minor mathematics, not as a 'correlational' concession to humans, but as an expression of an indifferent world which we encounter contingently. We cannot just bracket chance, for absolute contingency. We occupy a chance-inflected embodied event coordinated in such a manner so as to partake of mathematical worlds. This is a fortunate commingling that allows particular bodies, perhaps more than others, to indulge in or enjoy scientific knowledge as it evolves. In the next section, I turn to two mathematicians - Zalamea and Longo - who critique what they surmise is a continued fascination with philosophical 'foundations' in work like that of Badiou and Meillassoux, when contemporary mathematical practice reveals more about worldly mathematiz-ability.

\section{Metamorphic mixtures of matter-meaning}


Fernando Zalamea offers an aesthetic image of contemporary mathematics that I think seems fairly well-suited to an agential, lively and speculative materialism. Although Zalamea's book A synthetic philosophy of mathematics (2009) is very much a book about great (mostly white male) mathematicians, the overarching claim is that these people have succeeded in plugging into a metamorphic mathematical potentiality that joins their activity into a collective effort. Collaboration across mathematical communities occurs through "the exceptional protean capacity" of mathematics itself. The book proposes a "transitory ontology" for mathematics, and pursues a "continuity" between the phenomenal, the ontic, and the epistemic. This is a mathematics, according to Zalamea (2009), that is attentive to shifting and temporal unfolding, to gluing the global with the local, to tracking the "asymptotic webs of truth" across diverse conceptual developments (p. 142).

According to Zalamea (2009), collaboration across mathematical domains reflects the unity of mathematics, but also entails the emergence of new objects that constantly tear the field open. He offers a series of case studies, and claims:

The unity of mathematics expresses itself, not only in virtue of a common base upon which the All is reconstituted (set theory), but - before all else in the convergence of its methods and in the transfusing of ideas from one to another of its various webs. The penetration of algebraic methods into analysis, itself subordinated to topology, the ubiquitous geometrization of logic and the structural harmony of complex analysis with arithmetic, are all examples in which mathematics' global unity can be perceived in its local details. (Zalamea, 2009, p. 36-37)

Zalamea describes the field of mathematics in terms of fluid mixture - in discussing a whole raft of examples of mathematical developments, he uses words like "decantering", "pouring", "transfusing" "filtering", "saturating" and "distilling". Hence his attention to the ways in which the ideas transit from domain to domain, and metamorphize as they do. He argues that the radical transformation of mathematics in the $20^{\text {th }}$ century, due in large part to the mathematician Grothendiek's hugely influential algebraic methods, which emerged from group methods, intellectually corresponds to changes in physics, with the development of 
relativity theory. Any philosophy of mathematics worth its salt, he argues, must examine advanced mathematics and he reviews a set of philosophers and mathematicians who do that - such as Lautman, Badiou, Maddy, Cavaillès, Châtelet, Wilder, de Lorenzo, Polya, Lakatos, Maclane, Rota, Patras, Corfield, Tymoczko, Kitcher, and Kline.

Zalamea's project is very much a process philosophy of mathematics, intent on refusing a static or absolute idealism whereby mathematical concepts transcend and detach from the spatio-temporal world. In the case of Grothendieck, he finds what he calls a "practice of a relative mathematics" (p.140). This approach breaks with a static "absolute" mathematics ("in the style of Russell") and develops an image of mathematics in transition, so that the very concept of invariant becomes unanchored and relativized, as he engages with a register of universals that are said to be capable of unmooring themselves from any 'primordial' absolute. He supports these claims with reference to the particular technical practices employed: "In a technical manner, both Einstein and Grothendieck manipulate the frame of the observer and the partial dynamics of the agent in knowledge." (Zalamea, 2009, p.141).

He describes Grothendieck's method as involving a:

web of incessant transfers, transcriptions, translations of concepts and objects between apparent distant regions of mathematics, and secondly, an equally incessant search for invariants, proto-concepts and proto-objects behind the web of movements (Zalamea, 2009, p. 141).

Insofar as this is the creative force of Grothendieck, it is also for Zalamea a method of plugging into a "reticent structure" or "proto-geometry" that is in the batter itself, so to speak, articulated through the method that Grothendieck called "sounding out" (p. Zalamea, p.152). Grothendieck will state that "One of my passions has been to name the things that discover themselves to me, as a means of apprehending them ... this is not at all to fashion or build structures ... It is rather to express, as faithfully as we can, these things that we are in the midst of discovering and sounding out ..." (Grothendieck in Zalamea, p. 152-154). 
Thus the transit of mathematical knowledge is not simply an exchange but also onto-generative "sounding out" - a transit of knowledge is a creative act when a new mathematical object or technique comes into being, stirring up the mattermeaning mixture. This speaks to the speculative force of mathematics, but brings the ontology away from the absolute. According to Zalamea, this process of remixing is not well captured in elementary mathematics, but only in more advanced mathematics - and hence his critique of the analytic tradition and philosophies of mathematics that focus only on the meaning of statements like $7+5=12$ or on the classical foundational 'crises' of Cantor and Gödel. It's the rich contemporary concepts of topoi and categories that he turns to: "Topoi, which are something like parallel universes for the development of mathematics, are categorical environments sufficiently vast for the development of an entire sophisticated technology of the relative to be possible." (Zalamea, 2009, p. 141).

Zalamea also draws extensively on what he calls the "dynamic Platonism" of the philosopher Albert Lautman, an inspiration for Deleuze as well. Lautman showed how mathematics often develops through breaking up its own rigidity by remixing key pairings like continuous/discrete or symmetry/dissymmetry. New mathematical structures emerge through transits and collaborations that partake in that remixing.

The richness of mathematics is largely due to that elastic duplicity that permits, both technically and theoretically, its natural transit between the ideal and the real. (Zalamea, 2009, p.54)

Contrary notions (local/global, form/matter, container/contained, etc) dwell within groups, number fields, Riemann surfaces and many other constructions ... the contraries are not opposed to one another, but, rather, are capable of composing with one another so as to constitute those mixtures we call mathematics. (Zalamea, 2009, p. 58)

In discussing the mathematician Alain Conne's "Quiddital mathematics" - as well as mathematicians Michael Atiyah, Peter Lax, and Maxim Kontsevich - Zalamea suggests that some of this work points to a kind of "intensified, infinitely refined Pythagoreanism" (p.226). For Zalamea, this means that such work might support new 
insights into physico-mathematical objects, mapping new mixtures of number and matter. He argues that these new mathematical developments show how arithmetic and physics are woven together in ways that are not predetermined in advance; how the ubiquity of noncommutative processes in "actual nature" point to a "conceptual nature" (p.223). Notably, Zalamea is committed to a kind of progress whereby new maths can in fact enhance or improve our ability to mathematize. Zalamea suggests that the specific mathematical practices that have emerged in the last decades are an amplification of human "technical, imaginative and rational capacities" (p.375). In his words "the invasion of cohomologies, groups, and metrics" has been decisive in advancing this kind of metamorphic mathematics, and in enhancing our ability to model the material world (p. 373). In the next section I turn to the ways in which this "fluid" nature of mathematics engages with the digital and the discrete, in the work of Gregory Chaitin and Giuseppe Longo.

\section{Computation and continuity}

Mathematics seems to become enlarged, again and again, in Zalamea's interlacing process of transits, across the physical sciences, and across mathematical domains. Gregory Chaitin, widely known for his work in mathematics and computer science, describes himself as a contemporary Pythagorean, and suggests that a post-Gödel "open" and "creative" mathematics is at work in the world (Chaitin, 2012, p. 12-13). For Chaitin mathematics also undergoes a historical evolution, so that current styles emerging out of developments in the twentieth century, force us to realize that computers must be considered, in his terms, "a revolutionary new kind of mathematics." (Chaitin, 2012, p.33).

Notably, Chaitin is often an inspiration to current theorists of the computational universe, everyone from Stephen Wolfram (2002) to Patricia Clough (2016) and Luciana Parisi (2016), for he proclaims that the software universe runs on a math that "cannot provide certainty because it is not closed, mechanical, it is creative, plastic, open!" (Chaitin, 2012, p.29). He contrasts the "old" math of "Newtonian differential equations" with what he calls the "postmodern discrete algorithmic math" of computing, a mathematics that has "infinite complexity" (Chaitin, 2012, p. 34). 
Chaitin is a Pythagorean because he is not simply seeking to simulate living systems using mathematical 'systems biology', but rather wants to "find the simplest possible mathematical life-form" (Chaitin, 2012, p. 41). He states "Math itself evolves, math is completely organic" (Chaitin, 2012, p.88). This process of evolution, he asserts, is not simply a gradual continuation of mathematics, but entails radical invention, whereby mathematics becomes radically different: "each time it faces a significant new challenge, mathematics transforms itself" (Chaitin, 2012, p. 87). In other words, it mutates and may become unrecognizable to itself. This actualization of different kinds of mathematics is for Chaitin evidence of a small ' $m$ ' mathematics emergent in our environment, however he still subscribes to a capital " $M$ " mathematics that he describes as "static, eternal, and perfect" (Chaitin, 2012, p.75). Based on this claim, and some other clues, one finds lurking in Chaitin's writing, as in many speculative projects, a commitment and desire for a fixed and static absolute. Moreover, contemporary mathematics, in Chaitin's perspective, is more aligned with computational paradigms of computer science, rather than modern algebra, which makes his ideas appealing to those theorizing the relationship between mathematics and information (where matter and information are confounded).

The mathematician Giuseppe Longo (2015) critiques this image of a computational universe, and calls it a "flat" and "uni-dimensional" discrete-computational approach. Such an approach to the question of mathematiz-ability is built on Turing's project to build a logical-formal computing machine, and is therefore tied to a kind of axiomatic, set-theoretic and logical image of mathematics. Longo (2015) claims that these methods have "profoundly impaired the comprehension of biological phenomena" (p.7). He sees a kind of impoverished logic encoded into the software analysis of complex ecosystemic structures, and goes on to bemoan the dominance of an "arithmetical discrete/finite, decidable (and thus programmable) world view" (p. 8). Zalamea (2009) similarly states that "nothing could therefore be further from an understanding of mathematical invention than a philosophical posture that tries to mimic the set-theoretical analytic, and presumes to indulge in 'antiseptic' procedures as the elimination of the inevitable contradictions of doing mathematics or the reduction of the continuous/discrete dialectic." (p. 183-184). 
The question as to how our own human habits of mathematizing are linked to mathematics as a worlding process shifts, with Longo, back to the eco-biological. Longo (2015) emphasizes the "utterly human" concept of symmetry (and the breaking of symmetry) in mathematics, art and language, pointing to the "fundamental bilateral symmetry" that characterizes our animal bodies (p.11). To this he adds the claim that mathematics partakes in an "active relation to the world" captured in the ongoing developments of different kinds of measurement: classical, relativistic, and quantum (see also de Freitas, 2016 and de Freitas \& Sinclair, 2018, 2020). He suggests that noncommutative geometries might help us better comprehend ontogenetic biological processes, as cascades of symmetry changes. He goes so far as to say that there is a correspondence between mathematics (as a study of quantities organized in structures) and the cosmos, but decries that "this shouldn't be considered a new Pythagoreanism" (p.12). Mathematical ability, for Longo, entails a coordinated action with the world which resists us - the world says "no", and "channels our epistemic praxis, which is of an eminently organizational character ..." (p.13).

This "real friction with the world" enmeshes material processes with mathematics, a kind of geologic entailment that goes back to pre-human forms, whilst refusing any sort of immanent mathematical structure (p.16). Our brain and body are organized in such a way, whereby particular physiological structures and neural networks are both conditions for particular kinds of geometry, and simultaneously plastic, responsive and generative, allowing for new kinds of sensitivity to emerge. Longo (2015), for instance, considers a radically different alien mathematics produced if the usual kind of corporeal symmetry that we enjoy was absent (p. 18). Similarly, Ian Stewart (2017) argues that we consider the existence of a fully alien xenomathematics that is not simply equivalent to some version of our mathematics, modulo differences in notation and rule. In other words, xenomathematics would not be translatable into human mathematics. Stewart (2017) makes this claim compelling in two concrete scenarios: The first explores an alternative prime number system that would be essentially incomprehensible to us because it would involve such gigantic "computational cost" in terms of the amount of algorithmic and arithmetic work needed to translate it into our own mathematics. The second examines the fundamental aporia at the heart of any axiomatic system, adequate for arithmetic, focusing on problems that emerge, 
due to the axiom of choice and its alternatives. All of this suggests, for Stewart, that earthly mathematics is simply human - all too human - in its limitations.

Like Zalamea, Longo critiques the proposal that set theory is an ultimate foundation of mathematics, as this neglects the spatiality of situated mathematics. If the category of sets were the alleged ultimate universe of intelligibility, the mathematical concept of dimension would vanish into dust. For Longo, dimensionality "in the entire semantic richness of the word" is crucial for understanding worlds and worlding processes. Spatial dimension is implicated in any material process, he suggests, as though it were the condition of possibility. Notably, there is something deeply spatial in the theoretical 'turn' that mathematics has taken since Grothendieck (Zalamea, 2009). In contrast, set theory destroys the concept of dimension through isomorphisms that map $R^{n}$ to $\mathrm{R}$, and $N^{n}$ to $\mathrm{N}$. "These isomorphisms are essential to the theories in question: in the first case they allow us to speak of cardinality, in the second they allow the definition of a Universal Machine, of Turing's great ideas, which led to the production of compilers and operative systems of informatics." (p. 23). These isomorphisms are indeed essential for certain kinds of mathematics, for certain kinds of mathematics, and yet this uni-dimensional perspective, collapsing all finite isomorphic powers into its flat episteme, seems to shun the spatio-temporal density of matter.

Longo prefers an ontology that seeks the "natural" topology of "intervals", where the interval is that which forbids the absurd isomorphisms mentioned above. Emphasis on the interval relates to Longo's recent elaboration of the continuity/discrete debate (Longo, 2019), and recalls Deleuze's (1985) pursuit of the interval as that which is occupied by affection and intensity - The interval is also related to the Bergsonian centre of indetermination (p. 60). Longo suggests that the concept of the interval is at the empirical heart of mathematics, and generative of so much speculative mathematical invention (see also de Freitas, 2018). He states: "Now, the minimal structure that one needs to assume in order to correlate mathematics and the world is a topological invariance, that of dimension." (p.23). Thus it is the interval - classic instrument of measure, and dimension - that rescues the intelligibility of mathematics. This, suggests Longo, brings home the point that the discrete codifiable world of computation fails miserably to speak to the physical world of life processes. 
In related argument, Zalamea (2012), using the work of Charles Peirce, argues that the best way to understand the mathematics of the interval is to reimagine the mingling of chance and continuity. In this way, chance is not simply mathematized as that which breaks with the continuous and enthrones the probably (the thrown dice), through the work of statistics and the discrete, but also that which stitches together the continuous interval with abductive speculation - drawing from a vast surreal space of hypotheses.

This might be our best way to rethink the force of contingency somewhat differently to that of Meillassoux. Instead of a flat static mathematics of sets, Zalamea (2009, $2012)$ and Longo $(2015,2019)$ direct our attention to the work of mathematical activity - principally, the speculative act of abduction. Through the speculative act of abduction, we smudge the discontinuity and patch together both the mathematical continuum but also the cosmological continuum of life itself. Abduction is then not only a human faculty, but is an expression of a worldly preoccupation with continuity and chance, or synechism and tychism, which were the terms that Peirce used to describe his metaphysics of continuity and chance. For Peirce, continuity and chance are the two entangled metaphysical attributes of the world.

\section{Conclusion}

I've focused here on a mathematical capacity (a mathematiz-ability) that might animate the world in ways that are more-than-human, suggesting that a materialist but speculative ontology helps us understand mathematical behaviour broadly conceived. This is not a totalizable capacity waiting to be revealed, not a transcendent "miracle" explaining the unreasonable effectiveness of mathematics, for that would displace the essential contingency - or absolute contingency - of worlding mathematical processes. The capacity to mathematize does not belong to humans, although it is uniquely expressed in human habits of making models, simulations, measurements and other engagements with metamorphic mixtures. When looking across the contributions of Zalamea and Longo, we note a concerted effort to examine the ontological commitments entailed in contemporary mathematical practices, where they find robust creative gestures that bring forth new concepts and new transits. At this scale of practice, Longo draws our attention to the persistent power 
of the interval, and the generative tension between the discrete and the continuous, so that we might see more clearly how mathematics is always engaged with nontotalizing methods, in many of its more mundane gestures, and not only when mastering transfinite numbers in Cantorian set theory. Although unable here to do justice to the complexity of each of these perspectives, I hope to have sketched some possible paths forward for new materialist ontologies, as they think with mathematics.

This paper merely pokes at some of the more fascinating philosophical questions pertaining to mathematics, in the hope of engendering more deliberation about mathematical material practices, and with the aim of inviting more writing about the enigmatic relationship between mathematics and matter. To the extent that many people continue to believe, with some just cause, and following Wigner, that mathematics has some sort of uncanny effectiveness in describing our material world and predicting its future paths, we are left to ponder whether mathematical gestures are capable of actualizing a proto-mathematical realm of indeterminate potentiality or virtuality immanent to the empirical. Today there are proposals for a "post-empirical" physics which can determine its truth simply by attending to the internal coherence and aesthetic conditions of its mathematical models (see Kragh, 2015 for discussion). In Lost in Math: How beauty leads physics astray (2017), Sabine Hossenfelder reveals the extent to which contemporary physics has become obsessed with mathematical symmetries. These current debates regarding the enigmatic relationship between mathematics and matter underscore the ongoing relevance of Wigner's topic. There is no denying that humans are utterly invested in mathematizing that which they encounter, as a material-cultural habit with all kinds of risky consequences, but there is also a speculative force to mathematics that engages in radical worlding experiments. For this reason, we need more transdisciplinary studies on this topic, drawing from anthropology, philosophy, history and biology, exploring the nature of mathematical practices, be they expert, novice, maverick, or non-human.

\section{Bibliography}

Badiou, Alain (2006). Mathematics and philosophy. In S. Duffy, Virtual MathematicsThe Logic of Difference (pp. 187-208). Clinamen. 
Barad Karen (2007). Meeting the Universe Halfway: Quantum Physics and the Entanglement of Matter and Meaning. Durham: Duke University Press.

Barad, Karen (2017). On touching - the inhuman that therefore I am. Accessed on Jan. 15 , 2021, at http://www.fiveyears.org.uk/archive2/pages/276/Candice_Jacobs/On_Touching__The_Inhuman_That_Therefore.pdf

Chaitin, Gregory (2012). Proving Darwin: Making biology mathematical. NY: Vintage Books.

Clough, Patricia (2016). Rethinking race: Calculation, quantification, and measure. Cultural studies-Critical methodologies, 16(5), 435-441.

de Freitas, Elizabeth (2016). Number sense and calculating children: Multiplicity, measure and Mathematical monsters. Discourse: Studies in the Cultural Politics of Education, 37(5), 650-661.

de Freitas, Elizabeth (2017). Karen Barad's quantum ontology and posthuman ethics: Rethinking the concept of relationality, Qualitative Inquiry, 23 (9), https://doi.org/10.1177/1077800417725359

de Freitas, Elizabeth (2018). The mathematical continuum: A haunting problematic. The mathematics enthusiast, 15 (1-2), 148-158.

de Freitas, Elizabeth; Ferrera, Francesca \& Ferrari, Giulia (2019). The coordinated movements of collaborative mathematical tasks: The role of affect in transindividual sympathy. ZDM: International Journal of Mathematics Education, 51(2), 305-318.

de Freitas, Elisabeth \& Sinclair, Nathalie (2020). Measurement as relational, intensive, inclusive: Towards a minor mathematics. Journal of Mathematical Behavior. Open access: https://www.sciencedirect.com/science/article/pii/S0732312320300602 de Freitas, Elizabeth \& Sinclair, Nathalie (2018). The quantum mind: Alternative ways of reasoning with uncertainty. Canadian Journal of Science, Mathematics and Technology Education, 18(3), 271-283.

Deleuze, Gilles (1994). Difference and repetition (Trans. Paul Patton). New York: Columbia University Press. 
Dolphijn, Rick \& Van der tuin, Iris (2012). New materialisms: Interviews and cartographies. Open Humanities Press. Accessed Jan. 15, 2021, at http://openhumanitiespress.org/books/download/Dolphijn-van-der-Tuin_2013_NewMaterialism.pdf

Drake, Stillman (1978). Galileo at work. Chicago: University of Chicago Press.

Drake, Stillman (1975). The role of music in Galileo's experiments. Scientific American, 232 (6), pp.98-105.

Ferreirós, José (2018). Wigner's "unreasonable effectiveness" in context. In M. Pitici (Ed.). The best writing on mathematics. Princeton: Princeton University Press. 130146.

Gribbin, John (2002). Science: A history. London: Penguin.

Johnson, George (2008). The ten most beautiful experiments. NY: Vintage.

Hossenfelder, Sabine (2017). Lost in math: How beauty leads physics astray. NY: Hachett Book Group.

Kirby, Vicky (2011). Quantum anthropologies: Life at large. Duke University Press.

Koyré, Alexandre (1977). Gallilean studies. The Harvester Press.

Kragh, Helge (2015). Why trust a theory? Accessible at https://www.whytrustatheory2015.philosophie.uni-

muenchen.de/program/index.html\#kragh

Meillassoux, Quentin (2008). After finitude: An essay on the necessity of contingency. Trans. Ray Brassier. NY: Continuum.

Meillassoux, Quentin (2015). Science fiction and extro-science fiction. Paris: Univocal. Longo, Giuseppe (2015). Synthetic philosophy of mathematics and natural sciences: Conceptual analyses from a Grothendiekian perspective. Speculations. Accessed at https://www.di.ens.fr/users/longo/

Longo, Giuseppe (2019). Quantifying the world and its webs: Mathematical discrete versus continua in knowledge construction. Theory, Culture, Society. 36(6), 63-72. 
Parisi, Luciana (2016). Automated thinking and the limits of reason. Cultural studiesCritical methodologies, 16 (5), 471-481.

Scholz, Erhard (2006). Introducing groups into quantum theory (1926-1930). Historia Mathematica, 33, 440-490.

Stewart, Ian (2017). Xenomathematics. In B. Sriraman (Ed). Humanizing mathematics and its philosophy: Essays celebrating the $90^{\text {th }}$ birthday of Reuben Hirsh. Springer.

Wigner, Eugene (1960). The unreasonable effectiveness of mathematics in the natural sciences. In Communications in Pure and Applied Mathematics, vol. 13, No. I (February). New York: John Wiley \& Sons.

Wolfram, Stephen (2002). A new kind of science. Champagne, IL: Wolfram Media.

Zalamea, Fernando (2009). A synthetic philosophy of mathematics. (Trans. Zachery Luke Fraser). NY: Sequence Press.

Zalamea, Fernando (2012). Peirce's logic of continuity. Boston: Boston MA. Docent Press.

\section{Author Information}

Elisabeth de Freitas (L.de-freitas@mmu.ac.uk)

Elizabeth de Freitas's research focuses on philosophical investigations of mathematics, science and technology, pursuing the implications and applications of this work across the humanities and social sciences. Her research has been funded by the Canada Council for the Arts, the U.S. National Science Foundation, the UK Economic and Social Research Council, and the Social Sciences and Humanities Research Council of Canada. She has published 3 books and over 50 chapters and articles. She is a professor at Manchester Metropolitan University and Adelphi University. 